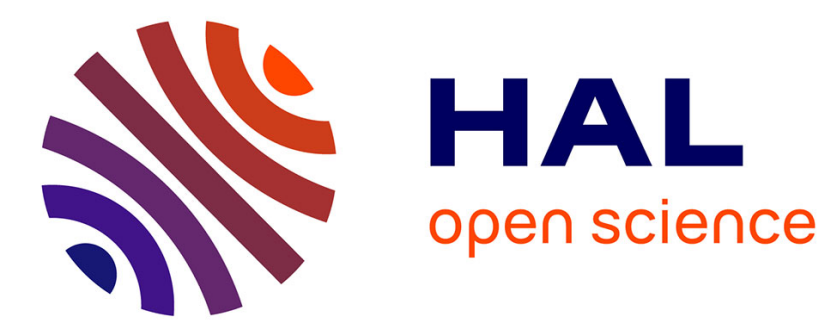

\title{
Durability study of a fluorescent optical memory in glass studied by luminescence spectroscopy
}

\author{
Arnaud Royon, Kevin Bourhis, Laurent Béchou, Thierry Cardinal, Lionel \\ Canioni, Yannick Deshayes
}

\section{To cite this version:}

Arnaud Royon, Kevin Bourhis, Laurent Béchou, Thierry Cardinal, Lionel Canioni, et al.. Durability study of a fluorescent optical memory in glass studied by luminescence spectroscopy. Microelectronics Reliability, 2013, 53 (9-11), pp.1514-1518. 10.1016/j.microrel.2013.07.110 . hal-00932228

\section{HAL Id: hal-00932228 \\ https://hal.science/hal-00932228}

Submitted on 8 Mar 2018

HAL is a multi-disciplinary open access archive for the deposit and dissemination of scientific research documents, whether they are published or not. The documents may come from teaching and research institutions in France or abroad, or from public or private research centers.
L'archive ouverte pluridisciplinaire HAL, est destinée au dépôt et à la diffusion de documents scientifiques de niveau recherche, publiés ou non, émanant des établissements d'enseignement et de recherche français ou étrangers, des laboratoires publics ou privés.

\section{(1)(1) $\$(0)$}

Distributed under a Creative Commons Attribution - NonCommercial - ShareAlikel 4.0 


\title{
Durability study of a fluorescent optical memory in glass studied by luminescence spectroscopy
}

\author{
A. Royon ${ }^{\mathrm{a}, \mathrm{b}}$, K. Bourhis ${ }^{\mathrm{c}}$, L. Béchou ${ }^{\mathrm{a}}$, T. Cardinal ${ }^{\mathrm{c}}$, L. Canioni ${ }^{\mathrm{a}}$, Y. Deshayes ${ }^{\mathrm{b}, *}$ \\ ${ }^{a}$ Laboratoire Ondes et Matière d'Aquitaine, Université de Bordeaux, 351 Cours de la Libération, 33405 Talence cedex, France \\ ${ }^{\mathrm{b}}$ Laboratoire IMS, Université de Bordeaux, 351 Cours de la Libération, 33405 Talence cedex, France \\ ${ }^{\mathrm{c}}$ Institut de Chimie et de la Matière Condensée de Bordeaux, CNRS, Université de Bordeaux, 87 Avenue du Docteur Schweitzer, 33608 Pessac cedex, France
}

\begin{abstract}
A B S T R A C T
Thermal stress at $100{ }^{\circ} \mathrm{C}$ for more than $3168 \mathrm{~h}$ of a fluorescent optical memory composed of laser written silver nano clusters embedded in glass has been performed. Measurements of luminescence spectra have been carried out at different times, showing a decreasing and an increasing evolution of the red and the blue part of the spectrum, respectively. This evolution has been attributed to the diffusion and the reor ganization of different silver species inside the matrix, altering the internal electric field. Stark effect based modeling enables the degradation mode of the memory.
\end{abstract}

\section{Context and objectives}

The innovations of recent decades have largely increased stor age capacity on the media, CD, CD R and DVD R up to Blu Ray, but in contradiction, the lifetime of such new supports is not as good as the innovation could be engaged. In comparison with the Egyptian scribes let us one of the first archive that could be read after 5000 years. Taking into account reliability aspect, we are, in 2012, 5000 years behind compared to the Egyptian technology. But if we use the Egyptian technology to record all actual data it will take us more than 1 billion pyramids, which is not possible. The first time to failure of actual digital support is around 20 years, which does not meet the archivist requirement [1].

This last point is a real huge societal high stake because nowa days, no perennial solution for more than 20 years of storage ex ists. Many sectors in the economic and social life are directly affected by this problem. In particular we must mention the archi vists. Their interest is to find a media for storing information for a long term. From the PSN (Pérennité des Supports Numériques) group report "It becomes urgent to develop innovative materials for a long term information storage" (12/2009) [1].

The main objectives of the project consists in the determination of the sustainability of Ag doped glass material structured by fem tosecond laser regarding environmental stresses applied to archi val of digital data.

The structuration of glass matrix is based on silver clusters structured under the femtosecond laser beam leading to a fluores cence contrast (under the laser excitation) between the glassy ma trix and the aggregate phase dots. Some results of the LOMA, IMS

\footnotetext{
* Corresponding author. Tel.: +33 (5) 4000 2768; fax: +33 (5) 56371545

E-mail address: yannick.deshayes@ims-bordeaux.fr (Y. Deshayes).
}

and ICMCB Laboratories about silver elements in glassy matrix gave some positive return to engage the reliability study.

The solution proposed in this study could be used on new optical memory glass based structured by femtosecond laser in the bulk. The advantage of this new technics resides in the fact that memory is composed by only one material (Glass). No delamina tion, shear stresses, etc. could be observed in this structure. The only one phenomenon is the diffusion of silver clusters. This publication answers to this specific issue.

\section{Experimental setup}

Silver clusters are created by a pulse train from a near infrared (NIR) femtosecond laser focused with a microscope objective in side a femto photo luminescent (FPL) glass (Fig. 1). Such a photo sensitive glass belongs to the phosphate family and was initially designed for gamma irradiation dosimetry [2,3]. In the present case, the composition is slightly modified: It is a zinc phosphate glass containing silver ions [2] presenting an ultraviolet (UV) absorption band below $280 \mathrm{~nm}$. Detailed descriptions of its fabrica tion and properties can be found in the Methods. Following expo sure to a high repetition rate femtosecond pulse train, the glass presents a broad excitation band (300 $450 \mathrm{~nm}$ ). When excited by NUV radiation, it emits homogeneous white fluorescence that specifications (intensity, spectrum and lifetime) depend on the irradiation dose (fluency, number of pulses and repetition rate) [4 6]. This fluorescence is attributed to the presence of $A g_{m} x^{+}$sil ver clusters with the number of atoms $m<10$ and the ionization degree $x$ [5]. These silver clusters are created inside the focusing voxel (cf. Fig. 1A) and are arranged into a pipe shape along the propagation axis, with a length corresponding to the Rayleigh range $(10 \mu \mathrm{m})$ and a wall thickness of about $80 \mathrm{~nm}$. For a given 


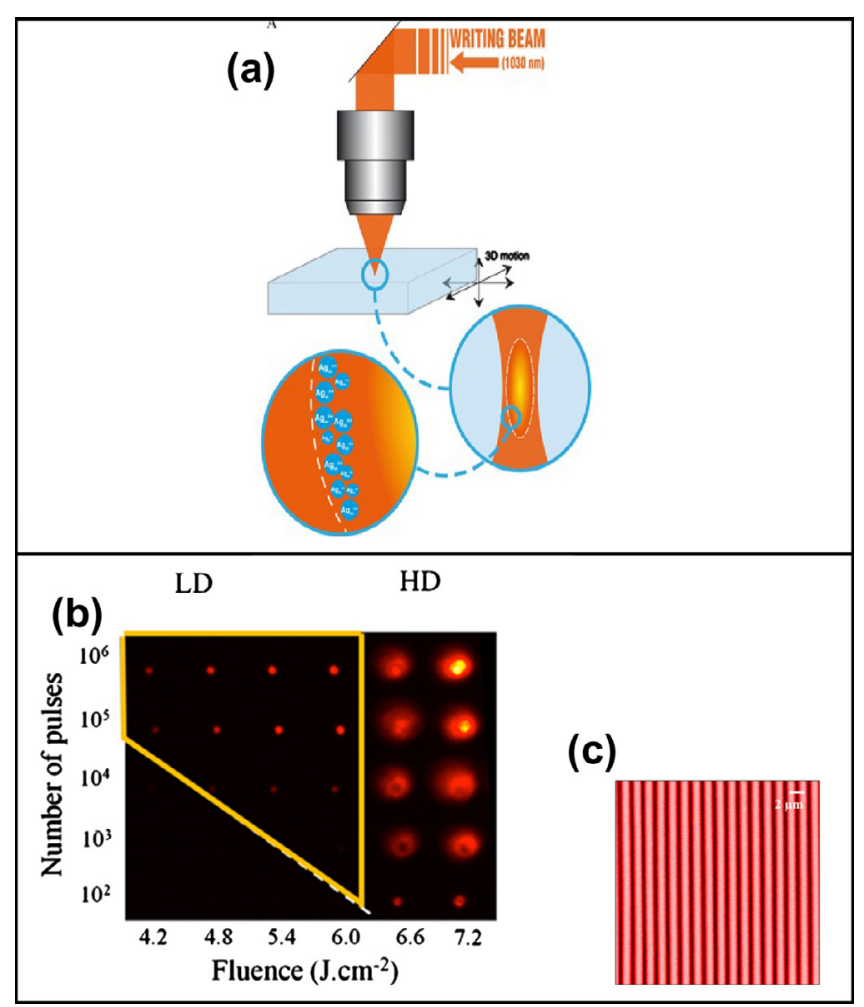

Fig. 1. (a) The laser interaction on Rayleigh range, (b) the separation between high dose (HD) and low dose (LD), and (c) the multiline structured by laser for each samples.

fluence range (from $2 \mathrm{~J} \mathrm{~cm}^{2}$ to $6 \mathrm{~J} \mathrm{~cm}^{2}$ ), the silver clusters are produced without significant linear refractive index change $\left(<10^{4}\right)$, while they exhibit appreciable fluorescence and nonlinear optical properties. This glass has already shown its potential for 3D optical data storage taking advantage of the third order suscepti bility contrast of the photo induced clusters with respect to the glass matrix [6,7].

The silver clusters can emit fluorescence intensities much high er (50 times) than fluorescent molecules such as dyes (Rhodamine $6 \mathrm{G}$ at $10^{4} \mathrm{~mol} \mathrm{~L}^{1}$ ). The quantum yield of these species is very high, on the order of $17 \%$. In the FPL glass, the emission can be tuned from yellow to red colors. The fluorescence time decay of the clusters is on the order of a few nanoseconds [4], allowing a reading speed as high as $500 \mathrm{MHz}$. In the FPL glass, the fluores cence intensity of the silver clusters varies linearly with the irradi ance and logarithmically with the deposited number of pulses, within the range of interest. This last behavior is well known in photographic processes [4]. Therefore, by adjusting properly the dose, the fluorescence intensity of the photo induced species can be controlled exactly like in silver photographic films.

\subsection{Glass preparation}

The glasses were made using a standard melt quench technique. Glass constituents in powder form were used as raw materials and the proper amount was placed in a platinum crucible. A heating rate of about $1{ }^{\circ} \mathrm{C}$ min ${ }^{1}$ was used up to $1000^{\circ} \mathrm{C}$. The melt was then kept at this last temperature $\left(1000^{\circ} \mathrm{C}\right)$ from 24 to $48 \mathrm{~h}$. Following this step, the liquid was poured into a brass mould after a short in crease of the temperature at $1100{ }^{\circ} \mathrm{C}$ in order to reach the appro priate viscosity. The glass samples obtained were annealed at $320^{\circ} \mathrm{C}\left(55^{\circ} \mathrm{C}\right.$ below the glass transition temperature) for $3 \mathrm{~h}$, cut (0.5 $1 \mathrm{~mm}$ thick) and optically polished.
The silver zinc phosphate glass and the silver silicate glass have the following compositions, respectively:

- $40 \mathrm{P}_{2} \mathrm{O}_{5} \quad 4 \mathrm{Ag}_{2} \mathrm{O} 55 \mathrm{ZnO} \quad 1 \mathrm{Ga}_{2} \mathrm{O}_{3}$ (mol\%).

- $69.98 \mathrm{SiO}_{2} \quad 1.27 \mathrm{Ag}_{2} \mathrm{O} \quad 16.37 \mathrm{Na}_{2} \mathrm{O} \quad 12.38 \mathrm{CaO}$ (mol\%).

These glasses possess an absorption cut off wavelength at $280 \mathrm{~nm}$ (due to the silver ions associated absorption band around $260 \mathrm{~nm}$ ) and emit fluorescence mainly around $365 \mathrm{~nm}$ when ex cited at $260 \mathrm{~nm}$. This intrinsic fluorescence is due to $\mathrm{Ag}^{+}$ions iso lated in the glass.

\subsection{Sample exposure}

The glass samples were irradiated using a femtosecond laser oscillator source (t Pulse 500, Amplitude Systèmes) emitting $500 \mathrm{fs}, 10 \mathrm{MHz}$ repetition rate pulses at $1030 \mathrm{~nm}$. The laser mode is $\mathrm{TEM}_{00}, M^{2}=1.2$ and the output polarization is TM. The maximum output average power is close to $6 \mathrm{~W}$, which results in a maximum energy per pulse of $600 \mathrm{~nJ}$. Acousto optic filtering permits the tun ing of the pulse energy, the number of pulses and the repetition rate for control of the cumulated effects. The laser beam was fo cused using a microscope objective (Zeiss Plan Apochromat 40×; $\mathrm{NA}=0.75)$ at a depth of $150 \mu \mathrm{m}$ in the glass. The beam waist was estimated to be $0.7 \mu \mathrm{m}$. The sample was manipulated using a mi cro precision $x y z$ stage (MicroControle MFA CC) with a repeatabil ity of $2 \mu \mathrm{m}$.

The $2 \mathrm{~mm} \times 2 \mathrm{~mm}$ sample is structured with 1000 lines sepa rated about $2 \mu \mathrm{m}$, at $150 \mu \mathrm{m}$ under surface. The speed recording is $1 \mathrm{~mm} \mathrm{~s}^{1}$. There are two different samples A and B:

- Sample A: The fluency is close to $6 \mathrm{~J} \mathrm{~cm}^{2}$ and the modification of refractive index is not effective $\left(\begin{array}{ll}10^{5} & 10^{4}\end{array}\right)$. It is the low dose sample (LD)

- Sample B: The fluency is close to $7 \mathrm{~J} \mathrm{~cm}^{2}$ and the modification of refractive index is effective $\left(\begin{array}{lll}1^{2} & 10^{1}\end{array}\right)$. It is the high dose sample (LD)

\subsection{Fluorescence measurements}

The fluorescence measurements are performed with single mode blue laser diode ( $364 \mathrm{~nm}$ ) and a Jobin Yvon TRIAX $320 \mathrm{spec}$ trometer. The resolution of spectrometer is $2.35 \mathrm{~nm} / \mathrm{mm}$ and the width of the laser diode is around $0.5 \mathrm{~nm}$. The reproducibility of measurement is estimated with a reference filter (Thorlabs FGL400). The optical spectra of sample have been corrected taking into account the reference white lamp and normalized to compare the spectral distribution. Fig. 2 gave the scheme of band structure of metal cluster.

\subsection{Reliability tests}

The ageing test are performed on Heraus climatic test chamber at $100{ }^{\circ} \mathrm{C} 3100 \mathrm{~h}$ corresponding to reference of passive storage realized by Laboratoire National de Metrologie et d'essais (LNE) [8].

The fluorescence measurements are realized before and after ageing test.

\section{Results and discussion}

\subsection{Model of luminescence}

Metal Ag clusters are molecular entity composed by few atoms and considered to be too small $(<2 \mathrm{~nm})$ for plasmonic resonance but having some specific fluorescence properties (Fig. 2). The 


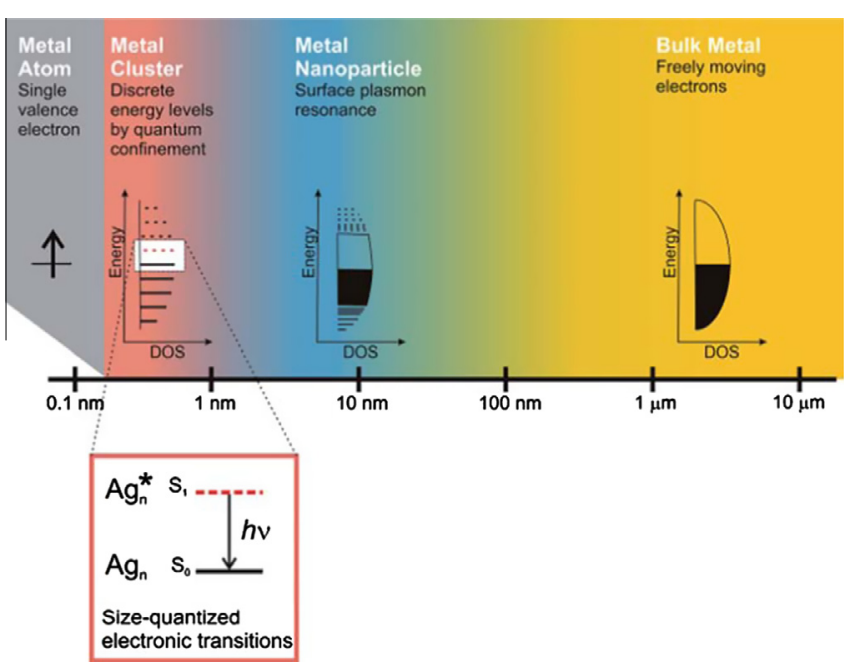

Fig. 2. Band structure of metal cluster.

interaction with light is operated by electronic transitions between different single energy level (as atomic level energy). In this case, the spontaneous emission rate is given by the following equation

$R_{\text {trans }}(E) \propto \frac{h^{2} \Gamma / 2}{\left(E_{0} \quad E\right)^{2}+h^{2}(\Gamma / 2)^{2}}$

$\Gamma$ represents the spectral bandwidth (FWHM) and $E_{0}$ is the band position.

The emission spectrum of nanoclusters depends on the host matrix where they are stabilized.

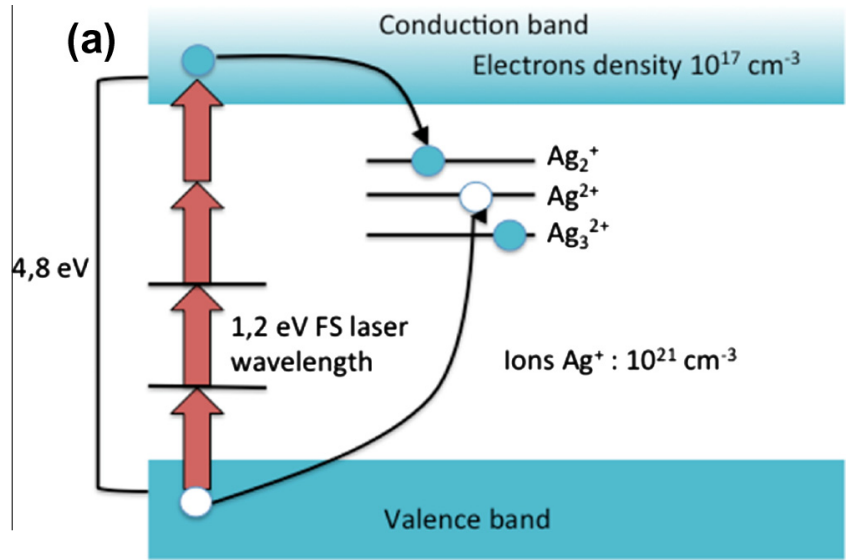

(b)

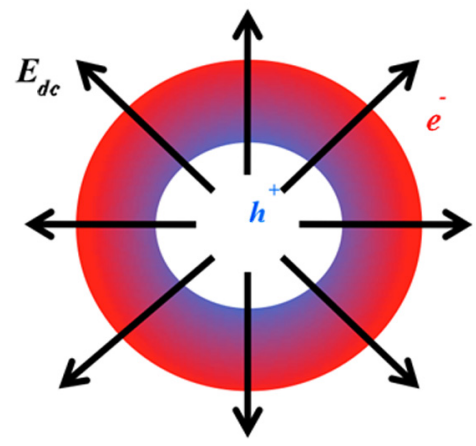

Fig. 3. Photoionisation process: band structure (a) electrical field direction in elementary structure (b).
The laser femtosecond interaction with matrix is driven by four photons absorption phenomenon (Fig. 3 a). The non linear absorp tion phenomenon generates electrons $\left(10^{17} \mathrm{~cm}^{3}\right)$ in the equiva lent conduction band of matrix. The $\mathrm{Ag}^{+}$ions $\left(10^{21} \mathrm{~cm}^{3}\right)$ located in the matrix (few percent) are:

Aggregated in $\mathrm{Ag}_{2}{ }^{2+}$ with one electron come from conduction band and gives $\mathrm{Ag}_{2}{ }^{+}$.

the $\mathrm{Ag}^{+}$form with hole generated in the equivalent valence band $\mathrm{Ag}^{2+}$.

$3 \mathrm{Ag}^{+}$are aggregate with one electron come from the equivalent conduction band.

These different charges generated by femtosecond laser diffused in the matrix to generate a donut as Fig. $3 \mathrm{~b}$ exposed and attached to the laser beam profile. This phenomenon is helped by the thermal heating of matrix due to the electron located in con duction band and thermally activated. After femtosecond laser pulse and thermal effect ended, the Ion located in the matrix give the electrical field presented in Fig. 3 b. Outside donut, the positive charges (aggregate) are fixed and activated by electrons during structuration while inside donut, the concentration in $\mathrm{Ag}^{+} \mathrm{de}$ creases and the equivalent charge became negative.

The luminescence phenomenon, activated by $325450 \mathrm{~nm}$ laser sources and given in Eq. (1), is modified by the electrical field by Stark effect [9] and the spontaneous emission is given by the fol lowing equation:

$$
\begin{aligned}
R_{\text {Stark }}(E) \propto & \left\{\left[\frac{d A_{i}(\xi)}{d \xi}\right]^{2}+\xi A_{i}^{2}(\xi)\right\} \\
& K \exp \left[\frac{4}{3}(\xi)^{3 / 2}\right]\left[(\xi)^{5 / 2}+8(\xi)^{1}\right]
\end{aligned}
$$

where $\xi$ is given by: $\xi \quad \frac{E \xi_{g}^{e f f}}{\xi}$ and $\xi \quad\left(\frac{2 m_{r}}{h^{2} q^{2} E_{d c}^{2}}\right)^{1 / 3}$.

The equivalent spectrum given by model, developed by Eqs. (1) and (2), considering different Ag clusters is given in Fig. 4. The dif ferent part associated to different phenomenon is underlined with wavelength correspondence. For Stark effect, the best fitting is ob served for wavelength ranging from 570 to $700 \mathrm{~nm}$. The inter level transition is given by Lorentzian curve (see Eq. (1)) observed for wavelength ranging from 350 to $570 \mathrm{~nm}$. In optical spectrum, the most important cluster concentration is generally repeated. Gener ally, one can only observed a typical Lorentzian curve.

\subsection{Experimental results}

The results of fluorescence response before and after ageing tests are shown in Fig. 2. For high dose (HD) samples (Fig. 5 a),

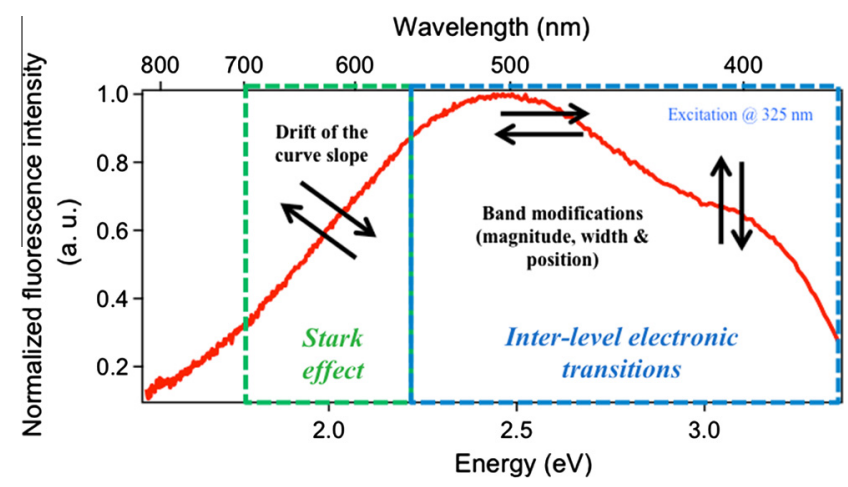

Fig. 4. Failure signatures on optical spectrum related to $\mathrm{Ag}_{x m}$ species modifications 

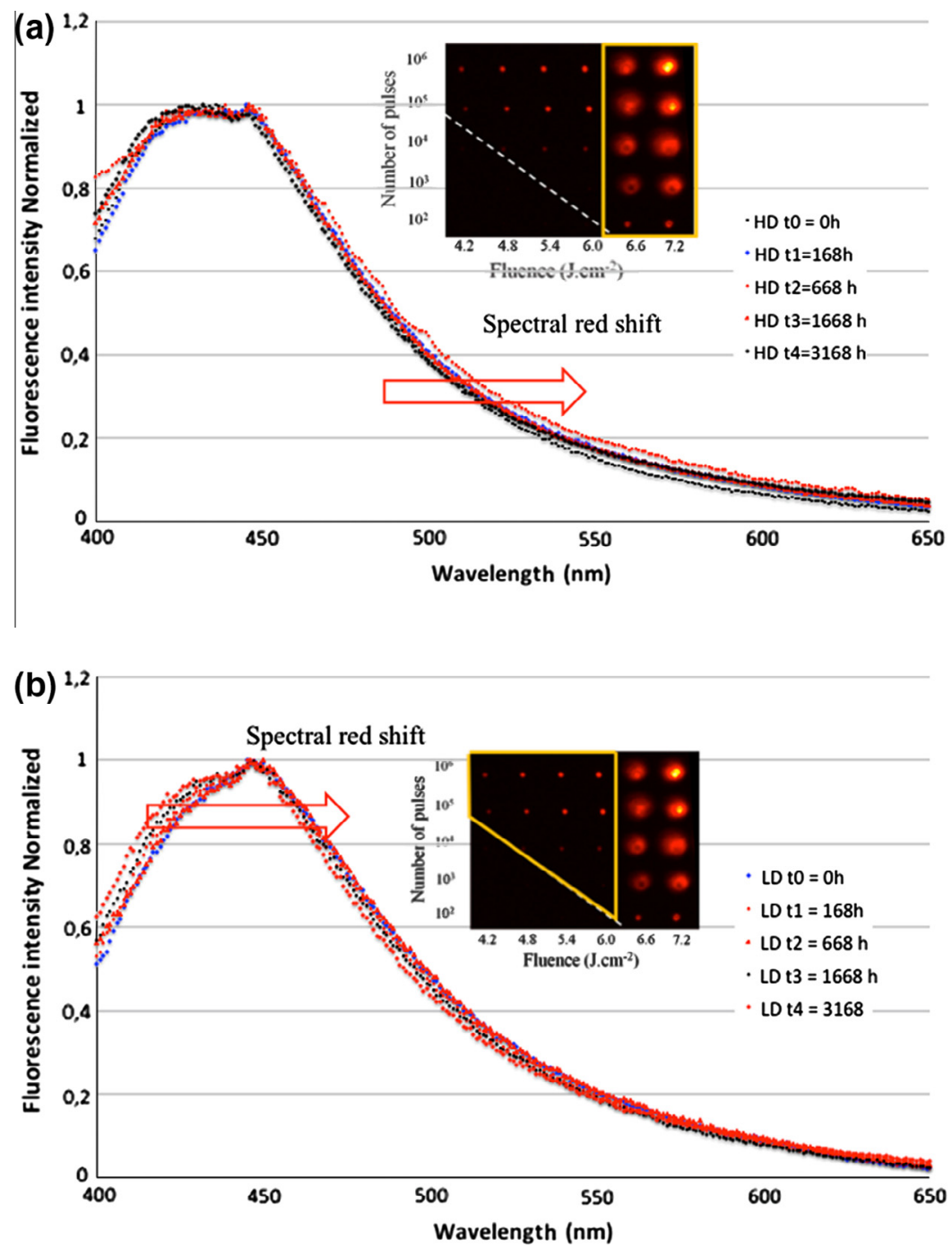

Fig. 5. Comparison between optical spectrum of HD (a) and LD (b) samples @ $300 \mathrm{~K}$ before and after ageing tests.

the impact of the spectral response is weak and only the red shift of high wavelength is observed. In this case, the Stark effect is modi fied in relation with electrical field. The modification of electrical field is closely related to the charge distribution in the matrix. The red shift is closely related to an increase of electrical field. The increase of electrical field is directly related to the diffusion of cluster. The diffusion of the cluster is in the good direction to in crease concentration of Ag cluster around the donut and increase the optical response of the system. System improves these perfor mances. There is no degradation but an increase of optical performances

For low dose (LD) samples (Fig. 5 b), the impact of the spectral response is weak and only a red shift of optical spectrum is ob served. In this case an $\mathrm{Ag}$ cluster is gradual change and explain the drift of $E_{0}$ position of the central energy. The modification of clusters no gradual changes optical performances of the system (less than $1 \%$ of the fluorescence).

\section{Conclusion}

These specific results are consistent with a long term reliability of optical memories. The spectral gradual change is mainly due to the modification of $\mathrm{Ag}$ cluster but the impact on optical perfor mances is very weak.
The impact on the performances is directly related to the elab oration and structuration of the samples. Both chemical composi tion and femtosecond laser parameters have been adjusted to find the optimized structure for reliability point of view. This pro cess is related to design for reliability, well established in industrial development. This original work shows that the design for reliabil ity is develop in the fundamental research for new optical memo ries. Based on these first results, many investigations will be engaged to find an industrial and long term optical memory based on commercial glass and laser.

\section{References}

[1] Spitz E, Hourcade JC, Laloë F. Préservation à long terme de l'information numérique Rapport du groupe PSN. Académie des Sciences et des Technologies; 2010. p. 51

[2] Royon A, Petit Y, Papon G, Richardson M, Canioni L. Femtosecond laser induced photochemistry in materials tailored with photosensitive agents [Invited]. Opt Mater Express 2011;1:866-82.

[3] Royon A, Bourhis K, Bellec M, Papon G, Bousquet B, Deshayes Y, et al. Silver clusters embedded in glass as a perennial high capacity optical recording medium. Adv Mater 2010:22:5282-6.

[4] Bellec M, Royon A, Bourhis K, Choi J, Bousquet B, Treguer M, et al. 3D patterning at the nanoscale of fluorescent emitters in glass. J Phys Chem C 2010;114:15584-8.

[5] Bourhis K, Royon A, Bellec M, Choi J, Fargues A, Treguer M, et al. Femtosecond laser structuring and optical properties of a silver-containing glass. J Non-Cryst Solids 2010;356:2658-65. 
[6] Bellec M, Royon A, Bousquet B, Bourhis K, Treguer M, Cardinal T, et al. Beat the diffraction limit in 3D direct laser writing in photosensitive glass. Opt Express 2009; 17:10304-18.

[7] Canioni L, Bellec M, Royon A, Bousquet B, Cardinal T. Three dimensional optical data storage using third-harmonic generation in silver zinc phosphate glass. Opt Lett 2008;33:360-2.

[8] Deshayes Y, Royon A, Baillot R, Béchou L, Canioni L, Petit Y, et al. Overview of thermal studies on photonics devices for reliability, robustness and new design, THERMINIC conférence, Budapest, 25-27 September; 2012 p. 13-18.

[9] Deshayes Y, Baillot R, Rehioui O, Béchou L, Gilard O, Ousten Y. Failure mechanisms in packaged light emitting diodes under Gamma radiations: Piezoelectric model based on Stark effect. IEEE Trans Mater Reliab 2011;11(2):303-11. 